\title{
FACTORS ASSOCIATED WITH ADHERENCE TO IMPLEMENTATION OF EARLY BREASTFEEDING INITIATION AMONG MIDWIVES AT ACEH TAMIANG GENERAL HOSPITAL, NORTH SUMATERA
}

\author{
Arie Willyana'), Juanita'), Destanul Aulia3) \\ ${ }^{1)}$ Masters Program in Hospital Administration, Faculty of Public Health, \\ Universitas Sumatera Utara \\ ${ }^{2)}$ Department of Health Policy and Administration, Faculty of Public Health, \\ Universitas Sumatera Utara
}

\begin{abstract}
Background: Breastfeeding has many health benefits for both the mother and infant. World Health Organization recommends the provision of mother's breast milk to infants within one hour of birth referred to as "early initiation of breastfeeding". It ensures that the infant receives the colostrum or "first milk" rich in protective factors. Midwives have an important role to help lactating mothers to implement early initiation of breastfeeding. This study aimed to examine factors associated with adherence to implementation of early breastfeeding initiation among midwives at Aceh Tamiang general hospital, North Sumatera.
\end{abstract}

Subjects and Method: This was a cross-sectional study conducted at Tamiang General Hospital, North Sumatera. A total of 46 midwives were selected for this study. The dependent variable was adherence to implementation early initiation of breastfeeding. The independent variable was competence. The confounding factors included among others availability of standard operating procedure. The data were collected by questionnaire and analyzed by a multiple logistic regression.

Results: Midwives with higher competence were more likely to adhere to the implementation early initiation of breastfeeding, after adjusting for confounding factors $(\mathrm{OR}=6.49 ; \mathrm{p}=0.002)$.

Conclusion: Competence is associated with adherence to the implementation early initiation of breastfeeding among midwives.

Keywords: early initiation of breastfeeding, competence, adherence, implementation, midwives.

\section{Correspondence:}

Arie Willyana. Masters Program in Hospital Administration, Faculty of Public Health, Universitas Sumatera Utara, Medan, North Sumatera.

Email: awil.azzhi@gmail.com. Mobile: 082160592020. 